\title{
Unit of insulin
}

National Diabetes Information Clearinghouse (NDIC)

\section{Definitions}

Insulin

Defined by National Diabetes Information Clearinghouse (NDIC)

\section{Source}

National Diabetes Information Clearinghouse (U.S.). (2009). The diabetes dictionary. [Bethesda, Md.]: U.S. Dept. of Health and Human Services, National Institutes of Health, National Institute of Diabetes and Digestive and Kidney Diseases, National Diabetes Information Clearinghouse.

The basic measure of insulin. $\boldsymbol{U}-\mathbf{1 0 0}$ insulin means 100 units of insulin per milliliter (mL) or cubic centimeter (cc) of solution. Most insulin made today in the United States is U-100. 